\title{
Interventions that Improve Body and Brain Bioenergetics for Parkinson's Disease Risk Reduction and Therapy
}

\author{
Mark P. Mattson ${ }^{\mathrm{a}, \mathrm{b}, *}$ \\ ${ }^{a}$ Laboratory of Neuroscience, National Institute on Aging Intramural Research Program, Baltimore, MD, USA \\ ${ }^{\mathrm{b}}$ Department of Neuroscience, Johns Hopkins University School of Medicne, Baltimore, MD, USA
}

\begin{abstract}
Studies of Parkinson's disease (PD) patients, animal models and pathogenic actions of genetic mutations that cause familial PD have established that neuronal bioenergetics are compromised with brainstem and midbrain monoaminergic neurons being particularly vulnerable. Peripheral insulin resistance and diabetes in midlife may increase the risk of PD, and diet and lifestyle changes that increase insulin sensitivity (exercise and intermittent energy restriction) can counteract neurodegenerative processes and improve functional outcome in animal models. Insulin sensitizing glucagon-like peptide 1 (GLP-1) analogs are beneficial in animal models of PD, and the results of an initial clinical trial in PD patients are promising. In addition to improving peripheral and brain energy metabolism, exercise, intermittent energy restriction and GLP-1 analogs may bolster neuronal adaptive stress response pathways that enhance neurotrophic signaling, DNA repair, proteostasis and mitochondrial biogenesis.
\end{abstract}

Keywords: Autonomic nervous system, autophagy, brainstem, exercise, GLP-1, insulin, intermittent fasting, mitochondrial biogenesis, synuclein

\section{ABBREVIATIONS}

GLP-1 : glucagon-like peptide 1

LRRK2 : leucine-rich repeat kinase 2

MPTP : 1-methyl-4-phenyl-1,2,3,6tetrahydropyridine

PD : : Parkinson's disease

\section{INTRODUCTION}

This introductory section provides a brief synopsis of the involvement of cellular and systemic metabolic derangements in the pathogenesis of Parkinson's disease (PD). Recent review articles on particular aspects of this broad topic are cited, and those articles cite orig-

\footnotetext{
*Correspondence to: Mark P. Mattson, Tel.: +410 558 8463; Fax: +410 558 8465; E-mail: mark.mattson@nih.gov.
}

inal research studies to which the interested reader can refer. The vast majority of research on PD has focused on substantia nigra dopaminergic neurons; this article will therefore focus on those neurons. However, it is clear that several other brain regions and neuronal populations are affected in PD. Indeed, recent findings suggest neurons in the brainstem are affected prior to dopaminergic neurons and that pathology 'spreads' from brainstem to midbrain to cerebral cortex. As a consequence, autonomic dysfunction resulting from brainstem pathology typically occurs before motor symptoms, while cognitive impairment associated with cerebral cortex pathology occurs later in the disease process [1-4]. I will therefore touch upon the effects of bioenergetics interventions on some of the nondopaminergic systems affected in PD.

Advances in identifying the genetic basis of inherited forms of PD have enabled investigations of the molecular and cellular mechanisms of action 
of the disease-causing mutations [5, 6]. The most intensively studied PD-causing mutations are autosomal dominant mutations in $\alpha$-synuclein (PARK1) and LRRK2 (PARK8), and autosomal recessive (lossof-function) mutations in Parkin (PARK2), PINK1 (PARK6) and DJ-1 (PARK7). In each case the mutation impairs mitochondrial bioenergetics, and compromises ubiquitin-mediated proteasome function and autophagy [7]. These newer molecular genetics-based findings dovetail nicely with previous studies of mitochondrial toxin-based models in which exposure of rodents or non-human primates to chemicals that inhibit complex 1 in the electron transport chain (MPTP, rotenone and 6-hydroxydopamine) results in degeneration of midbrain dopamine neurons [8]. Moreover, the genetic- and toxin-based models help explain why age is the major risk factor for late-onset PD. Thus, the major abnormalities that occur in neurons affected in PD (reduced complex 1 function and accumulation oxidatively damaged proteins) occur insidiously during normal aging.

From worms and flies, to rodents and monkeys, the aging process is accelerated by a high level of energy intake and is retarded by energy restriction [9-11]. In humans, being overweight increases the risk of all of the major diseases that result in premature death including diabetes, cardiovascular disease, stroke and cancers. Even without overt obesity, a metabolic syndrome characterized by insulin resistance, central adiposity and dyslipidemia increases the risk for all of the latter diseases. Recent findings suggest that the same metabolic syndrome may increase the risk of Alzheimer's disease $(\mathrm{AD})$ and $\mathrm{PD}$, particularly when the metabolic syndrome develops in midlife [12]. It was suggested 20 years ago that insulin resistance/diabetes accelerates deterioration of motor function, while inhibiting the effectiveness of levodopa treatment in PD patients [13]. Since then, multiple epidemiological studies suggest that insulin resistance and diabetes increase the risk of PD [14]. For example, a study of over 45,000 people in Finland demonstrated a positive association between body mass index and risk of PD [15], and a study in Denmark showed that having diabetes increased the risk of PD by nearly $40 \%$ [16]. The progression of neuropathology in PD may be accelerated by insulin resistance as suggested by a study showing that dementia is associated with insulin resistance in PD patients [17]. In addition to an elevation of peripheral insulin levels, levels of circulating IGF-1 (another indicator of a metabolically morbid state [18]) were elevated in PD patients and were correlated with motor symptom severity [19]. The latter findings suggest roles for
insulin/IGF-1 resistance in PD pathogenesis similar to what has been proposed for AD [20].

Only a few studies have evaluated the impact of insulin resistance on neuropathology and functional outcome in animal models of PD. Rats fed a diabetogenic high fat diet for 3 months developed insulin resistance and exhibited reduced evoked dopamine release in the striatum which was associated with increased iron deposition in the substantia nigra [21]. Feeding $\alpha$ synuclein mutant mice a diabetogenic diet (high in saturated fat and fructose) exacerbated dysfunction of the autonomic nervous system as indicated by decreased parasympathetic control of heart rate associated with increased $\alpha$-synculein accumulation in parasympathetic brainstem neurons [22]. These studies support the notion that insulin resistance and diabetes endanger dopaminergic neurons and other neurons affected in PD, a possibility bolstered by findings from studies described in the next section in which exercise and dietary energy restriction, two interventions that are well-known to increase insulin sensitivity and protect against diabetes, are beneficial in animal models of PD.

\section{EXERCISE AND ENERGY RESTRICTION}

The first approach to treating patients who are overweight and/or have type 2 diabetes should be to prescribe regular exercise and dietary restriction. Exercise (particularly vigorous aerobic exercise) and energy restriction (caloric restriction and intermittent fasting) can result in striking improvements in glucose and lipid metabolism, and can eliminate the need for drugs $[23,24]$. Exercise and energy restriction also reduce blood pressure, resting heart rate, inflammation and oxidative stress [25-27]. Insulin sensitivity of muscle and liver cells is enhanced by exercise and energy restriction in animal models and human subjects $[25,28,29]$. Exercise increases insulin-mediated glucose uptake into muscle cells by several mechanisms including stimulating the translocation of the glucose transporter GLUT4 to the plasma membrane [30]. Depolarization of the muscle cell membrane results in $\mathrm{Ca}^{2+}$ release from endoplasmic reticulum stores and $\mathrm{Ca}^{2+}$ influx through voltage-dependent channels in the plasma membrane. The $\mathrm{Ca}^{2+}$ then activates $\mathrm{Ca}^{2+}$ /calmodulin-dependent protein kinase II which up-regulates expression of GLUT4 [31]. In addition, exercise activates AMP-activated protein kinase (AMPK) which promotes insulin-dependent glucose uptake, mitochondrial biogenesis and fatty acid oxidation [32]. However, GLUT3 is the major glucose 
Table 1

Exercise and dietary energy restriction activate a wide range of adaptive cellular responses in peripheral organs and the brain, resulting in improved bioenergetics and brain function, and resistance to PD. Several major physiological responses to exercise and energy restriction (particularly intermittent fasting) are similar, and occur in peripheral cells and in brain cells

\begin{tabular}{|c|c|c|c|}
\hline \multicolumn{2}{|c|}{ Exercise } & \multicolumn{2}{|c|}{ Energy restriction* } \\
\hline Periphery (muscle, liver) & Brain (neurons) & Periphery (muscle, liver) & Brain (neurons) \\
\hline Insulin sensitivity & Insulin/IGF sensitivity & Insulin sensitivity & Insulin/IGF sensitivity? \\
\hline Ketogenesis & Ketone utilization & Ketogenesis & Ketone utilization \\
\hline Mitochondrial biogenesis & Mitochondrial biogenesis & Mitochondrial biogenesis & Mitochondrial biogenesis? \\
\hline VEGF, FGF2 & BDNF, FGF2, VEGF & VEGF, FGF2? & BDNF, FGF2 \\
\hline Protein chaperones & Protein chaperones & Protein chaperones & Protein chaperones \\
\hline Autophagy & Autophagy & Autophagy & Autophagy \\
\hline DNA repair & DNA repair & DNA repair & DNA repair? \\
\hline Improved bioenergetics & Improved bioenergetics & Improved bioenergetics & Improved bioenergetics \\
\hline Improved fitness & Enhanced neuroplasticity & Improved fitness & Enhanced neuroplasticity \\
\hline Reduced oxidative damage & Reduced oxidative damage & Reduced oxidative damage & Reduced oxidative damage \\
\hline Proteostasis & Proteostasis & Proteostasis & Proteostasis \\
\hline Reduced inflammation & Reduced inflammation & Reduced inflammation & Reduced inflammation \\
\hline Cardioprotection & Neuroprotection & Cardioprotection & Neuroprotection \\
\hline
\end{tabular}

*Energy restriction includes both daily caloric restriction and intermittent fasting [41, 139-145].

transporter in neurons and, with perhaps a few exceptions [33], most neurons express littleor no GLUT4. While it is unclear if and to what extent GLUT3 is similarly up-regulated by insulin in neurons, it was reported that insulin can stimulate the translocation of GLUT3 to the plasma membrane of neurons and that this effect of insulin enhances the ability of neurons to take up glucose in response to membrane depolarization [34].

Multiple beneficial effects of exercise and energy restriction on the brain have been documented (Table 1). Both types of intermittent energetic challenges reduce the risk of cerebrovascular disease [35]; improved cognitive function [36, 37]; enhanced neurogenesis [38]; and increased cellular stress resistance [39]. On the other hand, a sedentary and indulgent lifestyle increases the risk of stroke, and can impair cognitive function, neurogenesis and stress resistance [40-42]. Most of the studies of exercise, energy intake and diabetes on the brain have focused on the hippocampus, a brain region critical for learning and memory. As many of the cellular and molecular changes that occur in response to exercise and energy restriction are likely to occur in many different brain regions, including those most affected in PD, I will briefly summarize the results of studies of the hippocampus. Exercise induces the expression of brain-derived neurotrophic factor (BDNF), which plays a key role in hippocampal synaptic plasticity, neurogenesis and cognition [41, 43, 44]. Voluntary running wheel exercise and caloric restriction can increase the density of dendritic spines (synapses) in dentate granule neurons of both normal mice and dia- betic (leptin receptor mutant) mice [45]. Running and intermittent fasting also increase hippocampal neurogenesis [46, 47].

Exercise can protect neurons against dysfunction and degeneration in animal models relevant to $\mathrm{AD}[48$, 49], Huntington's disease (HD) [50, 51] (and see [52] for negative effects of exercise in an HD mouse) and stroke [53]. Intermittent fasting (alternate day food deprivation) protected hippocampal neurons against synaptic dysfunction in a transgenic mouse model of $\mathrm{AD}$ [54], in rat and mouse models of $\mathrm{HD}[55,56]$ and in a mouse model of focal ischemic stroke [57]. Inasmuch as the demise of neurons in AD and HD involves mechanisms shared with PD (oxidative stress, impaired cellular energy metabolism and excitotoxicity) it appears that exercise and energy restriction counteract such generic aspects of neurodegeneration. Indeed, studies have shown that exercise reduces oxidative stress [58], up-regulates the expression of genes encoding proteins involved in mitochondrial biogenesis [59] and DNA repair [60] in brain cells, and can protect neurons against excitotoxicity [55]. Intermittent fasting induces the expression of protein chaperones (HSP70 and GRP78), the antioxidant enzyme heme oxygenase 1, and the neurotrophic factors BDNF and fibroblast growth factor 2 in several brain regions [57, 61, 62]. In addition, intermittent fasting increases levels of ketone bodies, which are known to protect neurons against excitotoxic and metabolic stress $[63,64]$. BDNF, which is induced by both exercise and intermittent fasting, stimulates mitochondrial biogenesis [65] and DNA repair [60] in neurons which 
promotes synaptic plasticity and protects them against oxidative stress.

Accumulating evidence suggests that regular exercise can counteract the neurodegenerative process and may reduce the risk of PD and improve functional outcomes in PD patients [66-68]. In a prospective study of 77,254 women and 48,574 men, 135 women and 252 men were diagnosed with PD during the followup period. Vigorous exercise in early adult life was associated with a highly significant $60 \%$ lower PD risk in men, and a lower risk reduction in women [69]. In a study of 213,701 participants in the NIH-AARP Diet and Health Study, individuals who engaged in moderate to vigorous physical activity from the ages of $35-39$ or within the most recent 10 years had a $40 \%$ lower risk of developing PD compared to those who were relatively inactive [70]. On the other hand, analysis of data from 10,714 men in the Harvard Alumni Health Study did not reveal a statistically significant reduction in PD risk in those who exercised regularly, although the number of subjects with PD was relatively low [71].

Numerous studies have reported benefits of exercise for PD patients. PD patients maintained on either physiotherapist-supervised or self-supervised home exercise programs exhibited improved symptoms during an 8 week period [72]. High-intensity exercise for 8 weeks resulted in increased gait speed and stride length and improved weight distribution during sit-tostand transitions in PD patients [73]. Moreover, the PD patients in the high-intensity exercise group exhibited improved corticomotor excitability as indicated by lengthening of the cortical silent period in response to single-pulse transcranial magnetic stimulation. In another study of PD patients, a thrice weekly intensive 60 minute exercise program and a once weekly 60 minute adaptive exercise program each resulted in significant improvements in mobility and balance [74]. High intensity treadmill exercise improves gait and quality of life in PD [75], low intensity treadmill exercise improves gait speed but not muscle strength, whereas resistance exercise improves muscle strength but not gait speed [76]. Overall, the available data suggest that regular exercise during adult life can reduce the risk of PD modestly, and that exercise programs improve symptoms in PD patients. What has not been determined is if and how exercise affects PD-related pathogenic processes in the human brain. Interestingly, however, electrical stimulation of the subthalamic nucleus, a treatment that is effective in ameliorating symptoms in many PD patients, can improve peripheral glucose metabolism suggesting a link between neu- ral network dysfunction and the metabolic state in PD [77].

Studies of the effects of exercise and energy intake in animal models of PD have elucidated possible mechanisms whereby intermittent energetic challenges may protect against PD (Fig. 1). Exposure of mice to MPTP (1-methyl-4-phenyl1,2,3,6-tetrahydropyridine) results in degeneration of substantia nigra dopaminergic neurons, depletion of dopamine in the striatum and impaired corticospinal plasticity. Exercise protects dopaminergic neurons against MPTP toxicity in mice [78]. When treadmill running was initiated $5 \mathrm{~d}$ after MPTP lesioning and continued for 1 month, it resulted in improved balance on an accelerating rotarod compared to MPTPtreated mice that did not exercise [79]. Analysis of dopamine release using cyclic voltammetry showed greater stimulus-evoked release and less decay of dopamine in the dorsal striatum of exercised compared to non-exercised MPTP-treated mice. Daily 30-minute periods of wheel running exercise, 4-5 days/week attenuated MPTP-induced akinesia and hypokinesia, elevated BDNF levels in the parietal cortex and restored motor activity completely in L-Dopa-treated mice [80]. Exercise initiated after MPTP treatment restored $\mathrm{Ca}^{2+}$-impermeable AMPA receptor expression and corticostriatal plasticity [81]. In a mouse model of PD in which degeneration of dopaminergic neurons occurs over a protracted time period, 18 weeks of treadmill exercise reduced loss of dopaminergic neurons improved balance and coordination compared to non-exercised PD mice [82]. In the latter study, exercise elevated levels of BDNF and glial cell line-derived neurotrophic factor (GDNF) in the substantia nigra and striatum, which are two growth factors known to promote the survival of dopaminergic neurons. A critical role for BDNF in the anti-PD effect of exercise is supported by a study showing that exercise does not protect against MPTP neurotoxicity in BDNF heterozygous knockout mice [83]. Vigorous treadmill exercise also induced the expression of the dopamine D2 receptor in striatal neurons in MPTP-treated mice, suggesting that one mechanism of the therapeutic benefit of exercise in PD is to increase the sensitivity of striatal neurons to dopamine [84]. In addition, 4 weeks of treadmill exercise resulted in increased cerebral microvessel density in the striatum in MPTP-treated mice, suggesting a potential role for angiogenesis in the beneficial effects of exercise [85].

There is evidence that individuals with a high calorie intake are at increased risk of PD [86]. However, population-based studies have not revealed any clear 


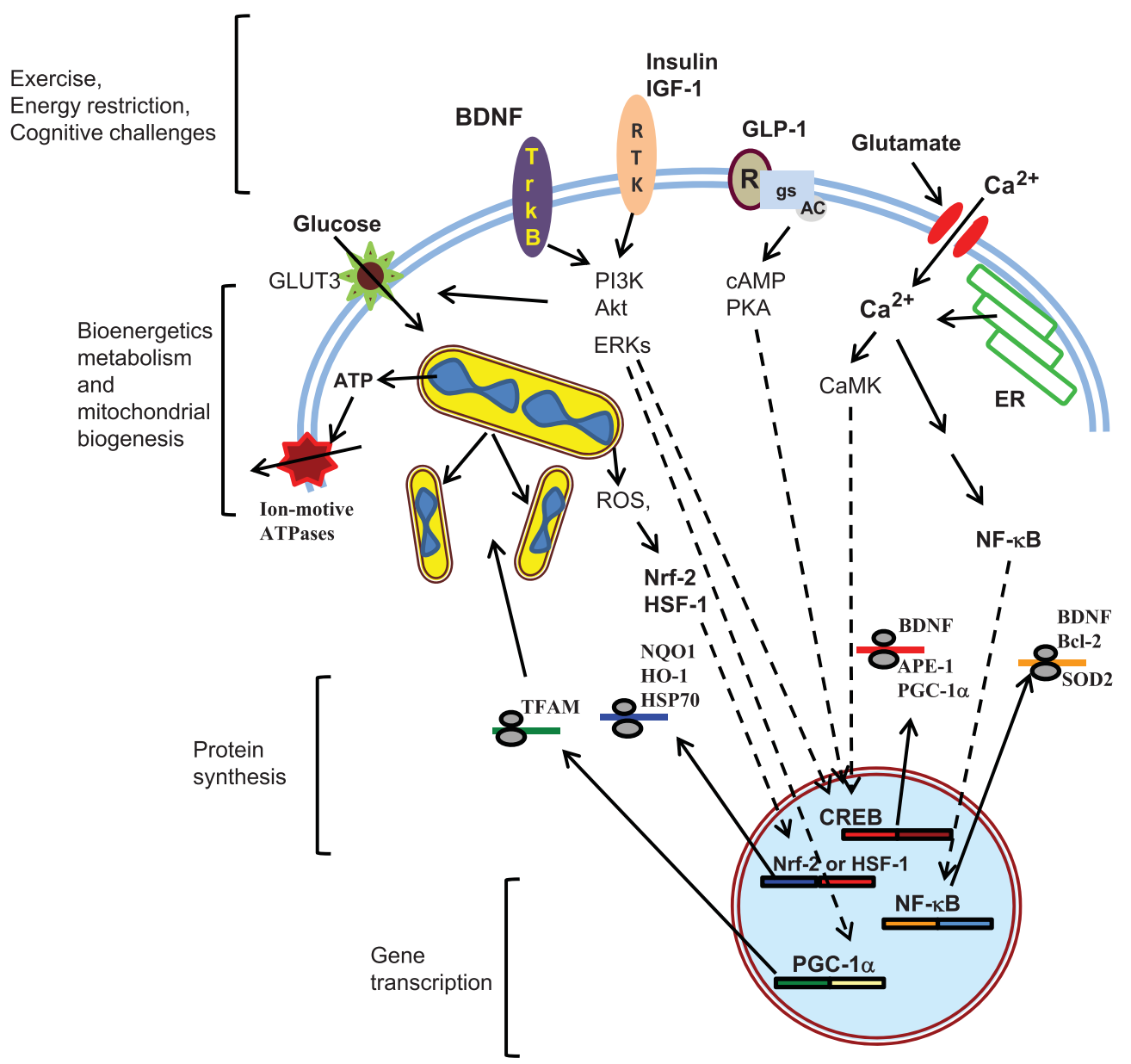

Fig. 1. Signaling pathways and molecular mechanisms that can improve neuronal bioenergetics and resistance to degeneration in PD. The glucose transporter protein GLUT3 moves glucose into neurons where it is used as the major substrate for ATP production in mitochondria. Neurons are highly excitable cells and so experience membrane depolarization $\left(\mathrm{Na}^{+}\right.$influx) and $\mathrm{Ca}^{2+}$ influx. A large amount of ATP is used by ion-motive ATPases to remove $\mathrm{Na}^{+}$and $\mathrm{Ca}^{2+}$ and thereby restore membrane potential to terminate $\mathrm{Ca}^{2+}$ signaling. Exercise, energy restriction and cognitive stimulation can engage several signaling pathways in neurons including activation of glutamatergic synapses resulting in $\mathrm{Ca}^{2+}$ influx through plasma membrane glutamate receptor channels, and production and release of brain-derived neurotrophic factor (BDNF) which activates its high-affinity receptor TrkB. $\mathrm{Ca}^{2+}$ influx can activate calcium/calmodulin-dependent protein kinase (CaMK) which, in turn, activates the transcription factor cyclic AMP response element-binding protein (CREB). CREB induces the expression of several genes that encode proteins involved in neuronal plasticity and stress resistance including BDNF, the DNA repair enzyme APE-1, and PGC-1 $\alpha$ which is a transcription factor that induces mitochondrial biogenesis. $\mathrm{Ca}^{2+}$ influx can also activate the transcription factor NF- $\kappa \mathrm{B}$ which induces the expression of BDNF, the anti-apoptotic protein Bcl-2, and the mitochondrial antioxidant enzyme SOD2. Exercise and energy restriction may also increase the sensitivity of neurons to insulin and insulin-like growth factor 1 (IGF-1) which activate receptor tyrosine kinases (RTK) coupled to phosphatidylinositol-3 kinase, Akt kinase and extracellular signal-regulated kinases (ERKs). Two downstream transcription factors that mediate responses to BDNF and insulin/IGF-1 are CREB and PGC-1 $\alpha$. Glucagon-like peptide 1 (GLP-1) activates receptors coupled to the GTP-binding protein Gs, which activates adenylate cyclase (AC) resulting in the production of cyclic AMP (cAMP) and protein kinase A (PKA), and PKA then activates CREB. Finally, reactive oxygen species (ROS) generated during mitochondrial respiration can activate the transcription factors Nrf-2 and heat shock factor 1 (HSF-1). The latter transcription factors induce the expression of genes encoding antioxidant enzymes such as $\mathrm{NAD}(\mathrm{P}) \mathrm{H}$ dehydrogenase (quinone 1) (NQO1) and heme oxygenase 1 (HO-1), and protein chaperones such as heat-shock protein 70 (HSP70).

association between obesity or diabetes and the risk of PD [87]. Nevertheless, dietary energy restriction is highly effective in protecting dopaminergic neurons and improving functional outcome in mouse and monkey models of PD. Mice maintained on an alternate day fasting diet exhibited reduced damage to dopaminergic neurons and less motor deficits in the MPTP PD model [88]. Once daily treatment of mice with 2-deoxyglucose, a nonmetabolizable glucose analog that induces cellular energetic stress similar to fast- 
ing, also protects neurons against MPTP which was associated with reduced oxidative stress, improved mitochondrial function and up-regulation of expression of the protein chaperone HSP-70 in neurons [88]. In a study of rhesus monkeys, one group was maintained on the usual diet and the calorie intake of another group was reduced by $30 \%$. After 6 months all monkeys received a single injection of MPTP into the right carotid artery and motor function, and levels of dopamine and neurotrophic factors were measured 3 months later. Monkeys in the calorie restriction group exhibited less motor deficits and higher levels of dopamine, BDNF and GDNF in their striatum [89]. Dietary restriction did not prevent the degeneration of dopaminergic neurons in the 6-hydroxydopamine model of PD [90], although only one high dose of 6-hydroxydopamine was used leaving open the possibility that energy restriction would protect against a lower level of exposure to this neurotoxin. Indeed, caloric restriction did protect dopaminergic neurons against 6-hydroxydopamine-induced degeneration in a $C$. elegans model by a mechanism mediated by the deacetylase Sir-2.1 [91].

Rare cases of PD result from mutations in, or overexpression of, $\alpha$-synuclein $[5,6]$. Mice expressing the PD-causing human $\alpha$-synuclein A53T mutation exhibit progressive motor impairment and some pathological changes including accumulation of $\alpha$-synuclein aggregates similar to PD patients [92]. While most of the focus in PD research has been on nigrostriatal dopaminergic neurons, brainstem autonomic (dorsal motor nucleus of the vagus) and monoaminergic neurons are often affected very early in the disease, even prior to the development of motor symptoms [93, 94]. Similar to PD patients, $\alpha$-synuclein mutant mice exhibit impaired brainstem autonomic function characterized by reduced parasympathetic control of heart rate [22]. The latter study showed that intermittent fasting ameliorates, whereas a high fat diet exacerbates, the brainstem cholinergic deficit. A high fat diet also increased the vulnerability of dopaminergic neurons to MPTP in mice [95]. Interestingly, A53T $\alpha$-synuclein mice exhibit abnormalities in energy metabolism characterized by reduced body weight gain when maintained on a high calorie diet, reduced accumulation of body fat, hypoleptinemia and increased energy expenditure [96]. The latter phenotypes have been noted in previous studies of PD patients [97], suggesting that $\alpha$-synuclein pathology may drive peripheral metabolic alterations.

While the results of studies of animal models provide compelling evidence that exercise and energy restriction, particularly intermittent fasting, can protect neurons against pathogenic processes relevant to $\mathrm{PD}$, rigorous studies in human subjects are lacking. Thus far, exercise studies have been relatively short term (typically $1-2$ months) and have evaluated only motor function, with no measurements of dopaminergic neuron function or biomarkers. There have been no interventional trials of intermittent fasting in PD patients.

\section{DIETARY SUPPLEMENTS AND DRUGS}

It is clear from studies of patients, disease-causing mutations and experimental models that vulnerable neurons in PD suffer a deficit of cellular energy which manifests in reduced levels of adenosine triphosphate (ATP) and nicotinamide adenine dinucleotide $\left(\mathrm{NAD}^{+}\right)$ [98]. One approach for protecting neurons in PD is to enhance the ability of neurons to maintain high levels of ATP and NAD ${ }^{+}$. Creatine, which is widely used as a dietary supplement by athletes [99] plays an important role in maintaining ATP levels in cells with a high metabolic demand, most notably muscle cells and neurons [100]. Creatine is synthesized from arginine and glycine, primarily in the liver and kidney, and is released into the blood and taken up by neurons. When administered prior to exposure to MPTP, creatine treatment can protect dopaminergic neurons and reduce motor deficits in mice $[101,102]$. Creatine can also protect the brain against traumatic injury [103], a risk factor for PD [104]. Clinical trials of creatine in PD patients have not demonstrated major ameliorative effects on motor symptoms, although other benefits have been noted including improved mood and a reduced need for escalation of levodopa dose [105].

Nicotinamide is a dietary supplement that can bolster cellular $\mathrm{NAD}^{+}$levels and can protect neurons against metabolic and excitotoxic insults [106]. Nicotinamide can also reduce the accumulation of, and protect neurons against, the neurotoxic amyloid $\beta$-peptide by a mechanism involving enhanced autophagy [107]. In mouse models of PD administration of nicotinamide prior to exposure to MPTP results in preservation of substantia nigra dopaminergic neurons and maintenance of striatal dopamine levels [108]. In an open-label study of 800 PD patients treated with nicotinamide adenine dinucleotide (which can increase cellular $\mathrm{NAD}^{+}$levels in animals) improvement in symptoms was noted in $80 \%$ of the patients [109]. However, large double-blind placebo-controlled 
trials of nicotinamide or NADH would be required to establish efficacy of this treatment approach.

The neuroprotective effects of ketogenic diets [110] and intermittent fasting which also elevate ketone levels [111], suggests a potential for ketogenic diets to be beneficial in preventing and/or treating PD. In one study a ketogenic diet protected dopaminergic neurons against 6-hydroxydopamine toxicity [112], while in another study administration of D- $\beta$-hydroxybutyrate (the major endogenously produced ketone body) to mice reduced neuronal degeneration and ameliorated motor deficits in the MPTP model [113]. Studies of ketogenic diets in PD patients remain to be performed.

Because exercise and dietary energy restriction improve insulin sensitivity and are neuroprotective [41, 114], it is reasonable to consider that drugs that increase insulin sensitivity might be beneficial for PD patients. A widely used drug for diabetes is metformin, which can increase the sensitivity of cells to insulin by increasing activity of AMP-activated protein kinase (AMPK) [115]. A study of 800,000 Taiwanese subjects indicated that diabetes patients treated with metformin have a reduced risk of PD compared to those not treated with metformin [116]. Another drug that increases insulin sensitivity is pioglitazone, which does so by activating the peroxisome proliferator activated receptor- $\gamma$ (PPAR- $\gamma$ ) [117]. Pioglitazone has demonstrated efficacy in reducing dopaminergic neuron degeneration and neuroinflammation, and improving functional outcome in the mouse MPTP and rat 6-hydroxydopamine PD models [118-123]. In a recent study, monkeys were subjected to unilateral intracarotid artery MPTP administration, their motor function was measured 24 hours later, and they were then assigned to pioglitazone ( $5 \mathrm{mg} / \mathrm{kg}$ once daily) or placebo groups. Three months later there was a significant improvement in motor function in the pioglitazone group compared to placebo [124]. When the authors examined the brains of the monkeys they found significantly greater levels of tyrosine hydroxylase in the striatum, less loss of nigral dopaminergic neurons and less neuroinflammation [124]. Whether such drugs will be evaluated in large-scale trials in PD patients remains to be determined.

When one eats a meal, the nutrients (particularly glucose) stimulate intestinal epithelial cells to release the 30 amino acid peptide GLP-1 (glucagon-like peptide 1 ) into the blood. GLP-1 exerts actions on pancreatic $\beta$-cells, and muscle and liver cells that enhance glucose removal from the blood. It increases the production by and release from $\beta$-cells, and it increases the insulin sensitivity of muscle and liver cells [125]. The half- life of GLP-1 in the blood is very short (1-2 minutes) because it cleaved and thereby inactivated by a circulating protease called DPP-IV. However, GLP-1 peptide analogs have been generated that are resistant to DPP-IV while retaining full GLP-1 receptor agonist activity. Two such GLP-1 analogs, Exendin4/Exenatide and liraglutide, were developed for the treatment of type 2 diabetes and have proven to be highly effective for that indication [126]. By improving whole body glucose metabolism GLP-1 analogs might be expected to benefit the brain. As it happens, however, GLP-1 receptors are widely expressed in neurons where their activation can be directly neuroprotective. For example, treatment of cultured hippocampal neurons with GLP-1 or Exendin-4 protects them against excitotoxicity, and treatment of rats with GLP-1 or exendin-4 protected forebrain cholinergic neurons against excitotoxin-induced death [127]. GLP-1 receptor agonists also protected cultured hippocampal neurons from being damaged and killed by amyloid $\beta$-peptide [128] and lessened neuropathologies in transgenic mouse models of AD [129-131]. Treatment of huntingtin mutant mice (a model of HD) with Exendin-4 improved glucose regulation and ameliorated neuropathological changes and motor dysfunction by a mechanism involving suppression of accumulation of huntingtin protein aggregates in pancreatic $\beta$-cells and striatal and cortical neurons [132]. Thus, GLP-1 receptor agonists are broadly neuroprotective in a range of experimental models of neurodegeneration.

GLP-1 receptors are coupled to the GTP-binding protein Gs and hence signal via a cyclic AMP-mediated pathway (Fig. 1). In neurons, activation of GLP-1 receptors results the activation of the transcription factor cyclic AMP response element binding protein (CREB) [133]. Because CREB is known to play important roles in synaptic plasticity and cell survival [134], it is likely that CREB mediates effects of GLP-1 receptor agonists on neuroplasticity and neuroprotection [135]. Indeed, CREB induces the expression of BDNF which is known to play key roles in neuroplasticity, and can protect many types of neurons, including dopaminergic neurons, against insults relevant to PD [136, 137]. Dopaminergic neurons express GLP-1 receptors and treatment of cultured dopaminergic neurons with GLP-1 or the long-acting GLP-1 analog Exendin-4 protects those neurons from being damaged by 6-hydroxydopamine [138]. Moroever, treatment of mice with Exendin-4 reduces neuronal degeneration and improves functional outcome in the MPTP model of PD [138]. Recently, an initial single-blind 
trial of Exendin-4 in PD patients was completed [114]. The PD patients were randomly assigned to Exendin4 treatment or control groups and were treated for 12 months and their symptoms were evaluated after overnight withdrawal of dopaminergic drugs at baseline, 6 months and 12 months. Whereas the symptoms of patients in the Exendin-4 group improved during the trial, the symptoms of those in the control group worsened. Collectively, the data from animal studies and the results of the initial clinical trial suggest that GLP-1 agonists hold potential as disease-modifying treatments for PD.

\section{CONCLUSIONS}

The findings described in this article suggest that interventions that improve peripheral and brain bioenergetics are beneficial for neurons vulnerable in PD including not only dopaminergic neurons, but also brainstem and cortical neuronal populations that are often affected in PD patients. It is becoming clear that regular exercise and moderation in energy intake (particularly intermittent fasting) promote optimal brain function and can reduce the risk of age-related brain disorders, including stroke, AD and PD [41]. Because of advances in the early diagnosis and effective treatment of cancers and cardiovascular disease, many more individuals are living beyond 70 years of age, the 'danger zone' for PD. Importantly, an overall worsening of healthy diets and lifestyles is sweeping the globe resulting in rapid increases in the incidence of obesity and diabetes. Because obesity and diabetes are risk factors for age-related cognitive deficits, and possibly PD, it is likely that the number of individuals with PD will continue to increase. Unfortunately, the general knowledge that sedentary gluttonous lifestyles increase the risks for cardiovascular disease, diabetes and premature death has not been sufficient motivation for the majority of people. Perhaps the prospects of developing AD and PD will be sufficient motivation for some individuals to adopt lifestyles that include regular exercise and intermittent energy restriction. Physicians should prescribe diet and exercise prescriptions that are doable, and follow-up vigorously to increase the odds of compliance using modern communication methods such as text messaging and social media [41]. Energy metabolism-modifying drugs that may counteract the neurodegenerative process in PD are being developed in preclinical studies and, in some cases, are being evaluated in clinical trials in PD patients. Among these, GLP-1 receptor agonists are particularly promising because they dramatically improve peripheral insulin sensitivity on the one hand, and act directly on neurons to enhance BDNF production and increase resistance to oxidative and metabolic stress.

\section{ACKNOWLEDGMENTS}

This work was supported by the Intramural Research Program of the National Institute on Aging, NIH.

\section{CONFLICT OF INTEREST STATEMENT}

The author has no conflicts of interest to disclose.

\section{REFERENCES}

[1] Braak H, Ghebremedhin E, Rüb U, Bratzke H, \& Del Tredici K (2004) Stages in the development of Parkinson's diseaserelated pathology. Cell Tissue Res, 318, 121-134.

[2] Maetzler W, Liepelt I, \& Berg D (2009) Progression of Parkinson's disease in the clinical phase: Potential markers. Lancet Neurol, 8, 1158-1171.

[3] Jellinger KA (2011) Synuclein deposition and non-motor symptoms in Parkinson disease. J Neurol Sci, 310, 107-111.

[4] Ulusoy A, Rusconi R, Pérez-Revuelta BI, Musgrove RE, Helwig M, Winzen-Reichert B, \& Di Monte DA (2013) Caudo-rostral brain spreading of $\alpha$-synuclein through vagal connections. EMBO Mol Med, 5, 1051-1059.

[5] Corti O, Lesage S, \& Brice A (2011) What genetics tells us about the causes and mechanisms of Parkinson's disease. Physiol Rev, 91, 1161-1218.

[6] Martin I, Dawson VL, \& Dawson TM (2011) Recent advances in the genetics of Parkinson's disease. Аппи Rev Genomics Hum Genet, 12, 301-325.

[7] Cook C, Stetler C, \& Petrucelli L (2012) Disruption of protein quality control in Parkinson's disease. Cold Spring Harb Perspect Med, 2(5), a009423.

[8] Duty S, \& Jenner P (2011) Animal models of Parkinson's disease: A source of novel treatments and clues to the cause of the disease. Br J Pharmacol, 164, 1357-1391.

[9] Martin B, Ji S, Maudsley S, \& Mattson MP (2010) "Control" laboratory rodents are metabolically morbid: Why it matters. Proc Natl Acad Sci U S A, 107, 6127-6133.

[10] Spindler SR (2010) Caloric restriction: From soup to nuts. Ageing Res Rev, 9, 324-353.

[11] Mercken EM, Carboneau BA, Krzysik-Walker SM, \& de Cabo R (2012) Of mice and men: The benefits of caloric restriction, exercise, and mimetics. Ageing Res Rev, 11, 390398.

[12] Santiago JA, \& Potashkin JA (2013) Shared dysregulated pathways lead to Parkinson's disease and diabetes. Trends Mol Med, 19, 176-186.

[13] Sandyk R (1993) The relationship between diabetes mellitus and Parkinson's disease. Int J Neurosci, 69, 125-130.

[14] Aviles-Olmos I, Limousin P, Lees A, \& Foltynie T (2013a) Parkinson's disease, insulin resistance and novel agents of neuroprotection. Brain, 136, 374-384.

[15] $\mathrm{Hu}$ G, Jousilahti P, Nissinen A, Antikainen R, Kivipelto M, \& Tuomilehto J (2006) Body mass index and the risk of Parkinson disease. Neurology, 67, 1955-1959. 
[16] Schernhammer E, Hansen J, Rugbjerg K, Wermuth L, \& Ritz B (2011) Diabetes and the risk of developing Parkinson's disease in Denmark. Diabetes Care, 34, 1102-1108.

[17] Bosco D, Plastino M, Cristiano D, Colica C, Ermio C, De Bartolo M, Mungari P, Fonte G, Consoli D, Consoli A, \& Fava A (2012) Dementia is associated with insulin resistance in patients with Parkinson's disease. J Neurol Sci, 315, 3943.

[18] Berryman DE, Glad CA, List EO, \& Johannsson G (2013) The GH/IGF-1 axis in obesity: Pathophysiology and therapeutic considerations. Nat Rev Endocrinol, 9, 346-356.

[19] Godau J, Knauel K, Weber K, Brockmann K, Maetzler W, Binder G, \& Berg D (2011) Serum insulinlike growth factor 1 as possible marker for risk and early diagnosis of Parkinson disease. Arch Neurol, 68, 925-931.

[20] De Felice FG (2013) Alzheimer's disease and insulin resistance: Translating basic science into clinical applications. $J$ Clin Invest, 123, 531-539.

[21] Morris JK, Bomhoff GL, Gorres BK, Davis VA, Kim J, Lee PP, Brooks WM, Gerhardt GA, Geiger PC, \& Stanford JA (2011) Insulin resistance impairs nigrostriatal dopamine function. Exp Neurol, 231, 171-180.

[22] Griffioen KJ, Rothman SM, Ladenheim B, Wan R, Vranis N, Hutchison E, Okun E, Cadet JL, \& Mattson MP (2013) Dietary energy intake modifies brainstem autonomic dysfunction caused by mutant $\alpha$-synuclein. Neurobiol Aging, 34, 928-935.

[23] Hensrud DD (2001) Dietary treatment and long-term weight loss and maintenance in type 2 diabetes. Obes Res, $\mathbf{9}$ (Suppl 4), 348S-353S.

[24] Sanz C, Gautier JF, \& Hanaire H (2010) Physical exercise for the prevention and treatment of type 2 diabetes. Diabetes Metab, 36, 346-351.

[25] Mattson MP, \& Wan R (2005) Beneficial effects of intermittent fasting and caloric restriction on the cardiovascular and cerebrovascular systems. J Nutr Biochem, 16, 129-137.

[26] Johnson JB, Summer W, Cutler RG, Martin B, Hyun DH, Dixit VD, Pearson M, Nassar M, Telljohann R, Maudsley S, Carlson O, John S, Laub DR, \& Mattson MP (2007) Alternate day calorie restriction improves clinical findings and reduces markers of oxidative stress and inflammation in overweight adults with moderate asthma. Free Radic Biol Med, 42, 665-674.

[27] Harvie MN, Pegington M, Mattson MP, Frystyk J, Dillon B, Evans G, Cuzick J, Jebb SA, Martin B, Cutler RG, Son TG, Maudsley S, Carlson OD, Egan JM, Flyvbjerg A, \& Howell A (2011) The effects of intermittent or continuous energy restriction on weight loss and metabolic disease risk markers: A randomized trial in young overweight women. Int J Obes (Lond), 35, 714-727.

[28] Shaw CS, Clark J, \& Wagenmakers AJ (2010) The effect of exercise and nutrition on intramuscular fat metabolism and insulin sensitivity. Аппи Rev Nutr, 30, 13-34.

[29] Bishop-Bailey D (2013) Mechanisms governing the health and performance benefits of exercise. Br J Pharmacol. doi: 10.1111/bph.12399 [Epub ahead of print].

[30] Frøsig C, \& Richter EA (2009) Improved insulin sensitivity after exercise: Focus on insulin signaling. Obesity (Silver Spring), 17(Suppl 3), S15-S20.

[31] Ojuka EO, Goyaram V, \& Smith JA (2012) The role of CaMKII in regulating GLUT4 expression in skeletal muscle. Am J Physiol Endocrinol Metab, 303, E322-E331.

[32] O'Neill HM (2013) AMPK and Exercise: Glucose uptake and insulin sensitivity. Diabetes Metab J, 37, 1-21.
[33] Apelt J, Mehlhorn G, \& Schliebs R (1999) Insulin-sensitive GLUT4 glucose transporters are colocalized with GLUT3expressing cells and demonstrate a chemically distinct neuron-specific localization in rat brain. J Neurosci Res, 57, 693-705.

[34] Uemura E, \& Greenlee HW (2006) Insulin regulates neuronal glucose uptake by promoting translocation of glucose transporter GLUT3. Exp Neurol, 198, 48-53.

[35] Kurth T, Moore SC, Gaziano JM, Kase CS, Stampfer MJ, Berger K, \& Buring JE (2006) Healthy lifestyle and the risk of stroke in women. Arch Intern Med, 166, 1403-1409.

[36] Cotman CW, \& Berchtold NC (2002) Exercise: A behavioral intervention to enhance brain health and plasticity. Trends Neurosci, 25, 295-301.

[37] Voss MW, Vivar C, Kramer AF, \& van Praag H (2013) Bridging animal and human models of exercise-induced brain plasticity. Trends Cogn Sci, 17, 525-544.

[38] van Praag H (2008) Neurogenesis and exercise: Past and future directions. Neuromolecular Med, 10, 128-140.

[39] Stranahan AM, \& Mattson MP (2012) Recruiting adaptive cellular stress responses for successful brain ageing. Nat Rev Neurosci, 13, 209-216.

[40] Stranahan AM, Arumugam TV, Cutler RG, Lee K, Egan JM, \& Mattson MP (2008) Diabetes impairs hippocampal function through glucocorticoid-mediated effects on new and mature neurons. Nat Neurosci, 11, 309-317.

[41] Mattson MP (2012) Energy intake and exercise as determinants of brain health and vulnerability to injury and disease. Cell Metab, 16, 706-722.

[42] McCrimmon RJ, Ryan CM, \& Frier BM (2012) Diabetes and cognitive dysfunction. Lancet, 379, 2291-2299.

[43] Gomez-Pinilla F, Vaynman S, \& Ying Z (2008) Brainderived neurotrophic factor functions as a metabotrophin to mediate the effects of exercise on cognition. Eur J Neurosci, 28, 2278-2287.

[44] Aguiar AS, Jr, Castro AA, Moreira EL, Glaser V, Santos AR, Tasca CI, Latini A, \& Prediger RD (2011) Short bouts of mild-intensity physical exercise improve spatial learning and memory in aging rats: Involvement of hippocampal plasticity via AKT, CREB and BDNF signaling. Mech Ageing Dev, 132, 560-567.

[45] Stranahan AM, Lee K, Martin B, Maudsley S, Golden E, Cutler RG, \& Mattson MP (2009) Voluntary exercise and caloric restriction enhance hippocampal dendritic spine density and BDNF levels in diabetic mice. Hippocampus, 19, 951-961.

[46] van Praag H, Kempermann G, \& Gage FH (1999) Running increases cell proliferation and neurogenesis in the adult mouse dentate gyrus. Nat Neurosci, 2, 266-270.

[47] Lee J, Duan W, \& Mattson MP (2002) Evidence that brain-derived neurotrophic factor is required for basal neurogenesis and mediates, in part, the enhancement of neurogenesis by dietary restriction in the hippocampus of adult mice. J Neurochem, 82, 1367-1375.

[48] Adlard PA, Perreau VM, Pop V, \& Cotman CW (2005) Voluntary exercise decreases amyloid load in a transgenic model of Alzheimer's disease. J Neurosci, 25, 42174221.

[49] Yuede CM, Zimmerman SD, Dong H, Kling MJ, Bero AW, Holtzman DM, Timson BF, \& Csernansky JG (2009) Effects of voluntary and forced exercise on plaque deposition, hippocampal volume, and behavior in the $\mathrm{Tg} 2576$ mouse model of Alzheimer's disease. Neurobiol Dis, 35, 426432. 
[50] Pang TY, Stam NC, Nithianantharajah J, Howard ML, \& Hannan AJ (2006) Differential effects of voluntary physical exercise on behavioral and brain-derived neurotrophic factor expression deficits in Huntington's disease transgenic mice. Neuroscience, 141, 569-584.

[51] van Dellen A, Cordery PM, Spires TL, Blakemore C, \& Hannan AJ (2008) Wheel running from a juvenile age delays onset of specific motor deficits but does not alter protein aggregate density in a mouse model of Huntington's disease. BMC Neurosci, 9, 34 .

[52] Potter MC, Yuan C, Ottenritter C, Mughal M, \& van Praag H (2010) Exercise is not beneficial and may accelerate symptom onset in a mouse model of Huntington's disease. PLoS Curr 2, RRN1201.

[53] Endres M, Gertz K, Lindauer U, Katchanov J, Schultze J, Schröck H, Nickenig G, Kuschinsky W, Dirnagl U, \& Laufs U (2003) Mechanisms of stroke protection by physical activity. Ann Neurol, 54, 582-590.

[54] Halagappa VK, Guo Z, Pearson M, Matsuoka Y, Cutler RG, Laferla FM, \& Mattson MP (2007) Intermittent fasting and caloric restriction ameliorate age-related behavioral deficits in the triple-transgenic mouse model of Alzheimer's disease. Neurobiol Dis, 26, 212-220.

[55] Bruce-Keller AJ, Umberger G, McFall R, \& Mattson MP (1999) Food restriction reduces brain damage and improves behavioral outcome following excitotoxic and metabolic insults. Ann Neurol, 45, 8-15.

[56] Duan W, Guo Z, Jiang H, Ware M, Li XJ, \& Mattson MP (2003) Dietary restriction normalizes glucose metabolism and BDNF levels, slows disease progression, and increases survival in huntingtin mutant mice. Proc Natl Acad Sci U SA, 100, 2911-2916.

[57] Arumugam TV, Phillips TM, Cheng A, Morrell CH, Mattson MP, \& Wan R (2010) Age and energy intake interact to modify cell stress pathways and stroke outcome. Ann Neurol, 67, 41-52.

[58] Marosi K, Bori Z, Hart N, Sárga L, Koltai E, Radák Z, \& Nyakas C (2012) Long-term exercise treatment reduces oxidative stress in the hippocampus of aging rats. Neuroscience, 226, 21-28.

[59] Steiner JL, Murphy EA, McClellan JL, Carmichael MD, \& Davis JM (2011) Exercise training increases mitochondrial biogenesis in the brain. $J$ Appl Physiol, 111, 1066-1071.

[60] Yang JL, Lin YT, Chuang PC, Bohr VA, \& Mattson MP (2013) BDNF and exercise enhance neuronal DNA repair by stimulating CREB-mediated production of apurinic/apyrimidinic endonuclease 1. Neuromolecular Med. [Epub ahead of print].

[61] Yu ZF, \& Mattson MP (1999) Dietary restriction and 2deoxyglucose administration reduce focal ischemic brain damage and improve behavioral outcome: Evidence for a preconditioning mechanism. J Neurosci Res, 57, 830-839.

[62] Duan W, Guo Z, \& Mattson MP (2001) Brain-derived neurotrophic factor mediates an excitoprotective effect of dietary restriction in mice. J Neurochem, 76, 619-626.

[63] Maalouf M, Rho JM, \& Mattson MP (2009) The neuroprotective properties of calorie restriction, the ketogenic diet, and ketone bodies. Brain Res Rev, 59, 293-315.

[64] Kashiwaya Y, Bergman C, Lee JH, Wan R, King MT, Mughal MR, Okun E, Clarke K, Mattson MP, \& Veech RL (2013) A ketone ester diet exhibits anxiolytic and cognitionsparing properties, and lessens amyloid and tau pathologies in a mouse model of Alzheimer's disease. Neurobiol Aging, 34, 1530-1539.
[65] Cheng A, Wan R, Yang JL, Kamimura N, Son TG, Ouyang X, Luo Y, Okun E, \& Mattson MP (2012) Involvement of PGC-1 $\alpha$ in the formation and maintenance of neuronal dendritic spines. Nat Commun, 3, 1250.

[66] Ahlskog JE (2011) Does vigorous exercise have a neuroprotective effect in Parkinson disease? Neurology, 77, 288-294.

[67] Archer T, Fredriksson A, \& Johansson B (2011) Exercise alleviates Parkinsonism: Clinical and laboratory evidence. Acta Neurol Scand, 123, 73-84.

[68] Speelman AD, van de Warrenburg BP, van Nimwegen M, Petzinger GM, Munneke M, \& Bloem BR (2011) How might physical activity benefit patients with Parkinson disease? Nat Rev Neurol, 7, 528-534.

[69] Chen H, Zhang SM, Schwarzschild MA, Hernán MA, \& Ascherio A (2005) Physical activity and the risk of Parkinson disease. Neurology, 64, 664-669.

[70] Xu Q, Park Y, Huang X, Hollenbeck A, Blair A, Schatzkin A, \& Chen $H$ (2010) Physical activities and future risk of Parkinson disease. Neurology, 75, 341-348.

[71] Logroscino G, Sesso HD, Paffenbarger RS, Jr, \& Lee IM (2006) Physical activity and risk of Parkinson's disease: A prospective cohort study. J Neurol Neurosurg Psychiatry, 77, 1318-1322.

[72] Lun V, Pullan N, Labelle N, Adams C, \& Suchowersky O (2005) Comparison of the effects of a self-supervised home exercise program with a physiotherapist-supervised exercise program on the motor symptoms of Parkinson's disease. Mov Disord, 20, 971-975.

[73] Fisher BE, Wu AD, Salem GJ, Song J, Lin CH, Yip J, Cen S, Gordon J, Jakowec M, \& Petzinger G (2008) The effect of exercise training in improving motor performance and corticomotor excitability in people with early Parkinson's disease. Arch Phys Med Rehabil, 89, 1221-1229.

[74] Gobbi LT, Oliveira-Ferreira MD, Caetano MJ, Lirani-Silva E, Barbieri FA, Stella F, \& Gobbi S (2009) Exercise programs improve mobility and balance in people with Parkinson's disease. Parkinsonism Relat Disord, 15(Suppl 3), S49-S52.

[75] Herman T, Giladi N, Gruendlinger L, \& Hausdorff JM (2007) Six weeks of intensive treadmill training improves gait and quality of life in patients with Parkinson's disease: A pilot study. Arch Phys Med Rehabil, 88, 1154-1158.

[76] Shulman LM, Katzel LI, Ivey FM, Sorkin JD, Favors K, Anderson KE, Smith BA, Reich SG, Weiner WJ, \& Macko RF (2013) Randomized clinical trial of 3 types of physical exercise for patients with Parkinson disease. JAMA Neurol, 70, 183-190.

[77] Batisse-Lignier M, Rieu I, Guillet C, Pujos E, Morio B, Lemaire JJ, Durif F, \& Boirie Y (2013) Deep brain stimulation of the subthalamic nucleus regulates postabsorptive glucose metabolism in patients with Parkinson's disease. $J$ Clin Endocrinol Metab, 98, E1050-E1054.

[78] Gerecke KM, Jiao Y, Pani A, Pagala V, \& Smeyne RJ (2010) Exercise protects against MPTP-induced neurotoxicity in mice. Brain Res, 1341, 72-83.

[79] Petzinger GM, Walsh JP, Akopian G, Hogg E, Abernathy A, Arevalo P, Turnquist P, Vucković M, Fisher BE, Togasaki DM, \& Jakowec MW (2007) Effects of treadmill exercise on dopaminergic transmission in the 1-methyl-4-phenyl1,2,3,6-tetrahydropyridine-lesioned mouse model of basal ganglia injury. J Neurosci, 27, 5291-5300.

[80] Fredriksson A, Stigsdotter IM, Hurtig A, Ewalds-Kvist B, \& Archer T (2011) Running wheel activity restores MPTPinduced functional deficits. J Neural Transm, 118, 407-420. 
[81] Kintz N, Petzinger GM, Akopian G, Ptasnik S, Williams C, Jakowec MW, \& Walsh JP (2013) Exercise modifies $\alpha$ amino-3-hydroxy-5-methyl-4-isoxazolepropionic acid receptor expression in striatopallidal neurons in the 1-methyl-4 -phenyl-1,2,3,6-tetrahydropyridine-lesioned mouse. J Neurosci Res, 91, 1492-1507.

[82] Lau YS, Patki G, Das-Panja K, Le WD, \& Ahmad SO (2011) Neuroprotective effects and mechanisms of exercise in a chronic mouse model of Parkinson's disease with moderate neurodegeneration. Eur J Neurosci, 33, 1264-1274.

[83] Gerecke KM, Jiao Y, Pagala V, \& Smeyne RJ (2012) Exercise does not protect against MPTP-induced neurotoxicity in BDNF haploinsufficient mice. PLoS One, 7(8), e43250.

[84] Vučković MG, Li Q, Fisher B, Nacca A, Leahy RM, Walsh JP, Mukherjee J, Williams C, Jakowec MW, \& Petzinger GM (2010) Exercise elevates dopamine D2 receptor in a mouse model of Parkinson's disease: In vivo imaging with $\left[{ }^{18}\right.$ F]fallypride. Mov Disord, 25, 2777-2784.

[85] Al-Jarrah M, Jamous M, Al Zailaey K, \& Bweir SO (2010) Endurance exercise training promotes angiogenesis in the brain of chronic/progressive mouse model of Parkinson's Disease. NeuroRehabilitation, 26, 369-373.

[86] Logroscino G, Marder K, Cote L, Tang MX, Shea S, \& Mayeux R (1996) Dietary lipids and antioxidants in Parkinson's disease: A population-based, case-control study. Ann Neurol, 39, 89-94.

[87] Palacios N, Gao X, McCullough ML, Jacobs EJ, Patel AV, Mayo T, Schwarzschild MA, \& Ascherio A (2011) Obesity, diabetes, and risk of Parkinson's disease. Mov Disord, 26 , 2253-2259.

[88] Duan W, \& Mattson MP (1999) Dietary restriction and 2deoxyglucose administration improve behavioral outcome and reduce degeneration of dopaminergic neurons in models of Parkinson's disease. J Neurosci Res, 57, 195-206.

[89] Maswood N, Young J, Tilmont E, Zhang Z, Gash DM, Gerhardt GA, Grondin R, Roth GS, Mattison J, Lane MA, Carson RE, Cohen RM, Mouton PR, Quigley C, Mattson MP, \& Ingram DK (2004) Caloric restriction increases neurotrophic factor levels and attenuates neurochemical and behavioral deficits in a primate model of Parkinson's disease. Proc Natl Acad Sci U S A, 101, 18171-18176.

[90] Armentero MT, Levandis G, Bramanti P, Nappi G, \& Blandini F (2008) Dietary restriction does not prevent nigrostriatal degeneration in the 6-hydroxydopamine model of Parkinson's disease. Exp Neurol, 212, 548-551.

[91] Jadiya P, Chatterjee M, Sammi SR, Kaur S, Palit G, \& Nazir A (2011) Sir-2.1 modulates 'calorie-restriction-mediated' prevention of neurodegeneration in Caenorhabditis elegans: Implications for Parkinson's disease. Biochem Biophys Res Commun, 413, 306-310.

[92] Crabtree DM, \& Zhang J (2012) Genetically engineered mouse models of Parkinson's disease. Brain Res Bull, 88, 13-32.

[93] Olanow CW, \& Tatton WG (1999) Etiology and pathogenesis of Parkinson's disease. Апnи Rev Neurosci, 22, 123-144.

[94] Kingsbury AE, Bandopadhyay R, Silveira-Moriyama L, Ayling H, Kallis C, Sterlacci W, Maeir H, Poewe W, \& Lees AJ (2010) Brain stem pathology in Parkinson's disease: An evaluation of the Braak staging model. Mov Disord, 25, 2508-2515.

[95] Bousquet M, St-Amour I, Vandal M, Julien P, Cicchetti F, \& Calon F (2012) High-fat diet exacerbates MPTP-induced dopaminergic degeneration in mice. Neurobiol Dis, 45, 529538.
[96] Rothman, S. M., K. J. Griffioen, K. W. Fishbein, R. G. Spencer, S. Makrogiannis, W. Cong, B. Martin and M. P. Mattson Rothman SM, Griffioen KJ, Fishbein KW, Spencer RG, Makrogiannis S, Cong W, Martin B, \& Mattson MP. (2013) Metabolic abnormalities and hypoleptinemia in $\alpha$-synuclein A53T mutant mice. Neurobiol pii: S01974580(13)00556-3. [Epub ahead of print].

[97] Lorefält B, Toss G, \& Granérus AK (2009) Weight loss, body fat mass, and leptin in Parkinson's disease. Mov Disord, 24, 885-890.

[98] Davey GP, Peuchen S, \& Clark JB (1998) Energy thresholds in brain mitochondria. Potential involvement in neurodegeneration. J Biol Chem, 273, 12753-12757.

[99] Brosnan JT, \& Brosnan ME (2007) Creatine: Endogenous metabolite, dietary, and therapeutic supplement. Аппи Rev Nutr, 27, 241-261.

[100] Klein AM, \& Ferrante RJ (2007) The neuroprotective role of creatine. Subcell Biochem, 46, 205-243.

[101] Matthews RT, Ferrante RJ, Klivenyi P, Yang L, Klein AM, Mueller G, Kaddurah-Daouk R, \& Beal MF (1999) Creatine and cyclocreatine attenuate MPTP neurotoxicity. Exp Neurol, 157, 142-149.

[102] Yang L, Calingasan NY, Wille EJ, Cormier K, Smith K, Ferrante RJ, \& Beal MF (2009) Combination therapy with coenzyme Q10 and creatine produces additive neuroprotective effects in models of Parkinson's and Huntington's diseases. J Neurochem, 109, 1427-1439.

[103] Sullivan PG, Geiger JD, Mattson MP, \& Scheff SW (2000) Dietary supplement creatine protects against traumatic brain injury. Ann Neurol, 48, 723-729.

[104] Jafari S, Etminan M, Aminzadeh F, \& Samii A (2013) Head injury and risk of Parkinson disease: A systematic review and meta-analysis. Mov Disord, 28, 1222-1229.

[105] Bender A, Koch W, Elstner M, Schombacher Y, Bender J, Moeschl M, Gekeler F, Müller-Myhsok B, Gasser T, Tatsch K, \& Klopstock T (2006) Creatine supplementation in Parkinson disease: A placebo-controlled randomized pilot trial. Neurology, 67, 1262-1264.

[106] Liu D, Gharavi R, Pitta M, Gleichmann M, \& Mattson MP (2009) Nicotinamide prevents NAD+ depletion and protects neurons against excitotoxicity and cerebral ischemia: NAD+ consumption by SIRT1 may endanger energetically compromised neurons. Neuromolecular Med, 11, 28-42.

[107] Liu D, Pitta M, Jiang H, Lee JH, Zhang G, Chen X, Kawamoto EM, \& Mattson MP (2013) Nicotinamide forestalls pathology and cognitive decline in Alzheimer mice: Evidence for improved neuronal bioenergetics and autophagy procession. Neurobiol Aging, 34, 1564-1580.

[108] Anderson DW, Bradbury KA, \& Schneider JS (2008) Broad neuroprotective profile of nicotinamide in different mouse models of MPTP-induced parkinsonism. Eur J Neurosci, 28, 610-617.

[109] Birkmayer JG, Vrecko C, Volc D, \& Birkmayer W (1993) Nicotinamide adenine dinucleotide (NADH)-a new therapeutic approach to Parkinson's disease. Comparison of oral and parenteral application. Acta Neurol Scand Suppl, 146, 32-35.

[110] Kossoff EH, \& Hartman AL (2012) Ketogenic diets: New advances for metabolism-based therapies. Curr Opin Neurol, 25, 173-178.

[111] Longo VD, \& Mattson MP. (2014) Fasting: Molecular mechanisms and clinical applications. Cell Metab. In press.

[112] Cheng B, Yang X, An L, Gao B, Liu X, \& Liu S (2009) Ketogenic diet protects dopaminergic neurons against 6-OHDA 
neurotoxicity via up-regulating glutathione in a rat model of Parkinson's disease. Brain Res, 1286, 25-31.

[113] Tieu K, Perier C, Caspersen C, Teismann P, Wu DC, Yan SD, Naini A, Vila M, Jackson-Lewis V, Ramasamy R, \& Przedborski S (2003) D-beta-hydroxybutyrate rescues mitochondrial respiration and mitigates features of Parkinson disease. J Clin Invest, 112, 892-901.

[114] Aviles-Olmos I, Dickson J, Kefalopoulou Z, Djamshidian A, Ell P, Soderlund T, Whitton P, Wyse R, Isaacs T, Lees A, Limousin P, \& Foltynie T (2013b) Exenatide and the treatment of patients with Parkinson's disease. J Clin Invest, 123, 2730-2736.

[115] Hardie DG (2011) Sensing of energy and nutrients by AMPactivated protein kinase. Am J Clin Nutr, 93, 891S-896S

[116] Wahlqvist ML, Lee MS, Hsu CC, Chuang SY, Lee JT, \& Tsai HN (2012) Metformin-inclusive sulfonylurea therapy reduces the risk of Parkinson's disease occurring with Type 2 diabetes in a Taiwanese population cohort. Parkinsonism Relat Disord, 18, 753-758.

[117] Cho N, \& Momose Y (2008) Peroxisome proliferatoractivated receptor gamma agonists as insulin sensitizers: From the discovery to recent progress. Curr Top Med Chem, 8, 1483-1507.

[118] Breidert T, Callebert J, Heneka MT, Landreth G, Launay JM, \& Hirsch EC (2002) Protective action of the peroxisome proliferator-activated receptor-gamma agonist pioglitazone in a mouse model of Parkinson's disease. J Neurochem, 82, 615-624.

[119] Dehmer T, Heneka MT, Sastre M, Dichgans J, \& Schulz JB (2004) Protection by pioglitazone in the MPTP model of Parkinson's disease correlates with I kappa B alpha induction and block of NF kappa B and iNOS activation. $J$ Neurochem, 88, 494-501.

[120] Quinn LP, Crook B, Hows ME, Vidgeon-Hart M, Chapman H, Upton N, Medhurst AD, \& Virley DJ (2008) The PPARgamma agonist pioglitazone is effective in the MPTP mouse model of Parkinson's disease through inhibition of monoamine oxidase B. Br J Pharmacol, 154, 226-233.

[121] Carta AR, Frau L, Pisanu A, Wardas J, Spiga S, \& Carboni E (2011) Rosiglitazone decreases peroxisome proliferator receptor- $\gamma$ levels in microglia and inhibits TNF- $\alpha$ production: New evidences on neuroprotection in a progressive Parkinson's disease model. Neuroscience, 194, 250-261.

[122] Ulusoy GK, Celik T, Kayir H, Gürsoy M, Isik AT \& Uzbay TI (2011) Effects of pioglitazone and retinoic acid in a rotenone model of Parkinson's disease. Brain Res Bull, 85, 380-384.

[123] Sadeghian M, Marinova-Mutafchieva L, Broom L, Davis JB, Virley D, Medhurst AD, \& Dexter DT (2012) Full and partial peroxisome proliferation-activated receptor- $\gamma$ agonists, but not $\delta$ agonist, rescue of dopaminergic neurons in the 6-OHDA parkinsonian model is associated with inhibition of microglial activation and MMP expression. J Neuroimmunol, 246, 69-77.

[124] Swanson CR, Joers V, Bondarenko V, Brunner K, Simmons HA, Ziegler TE, Kemnitz JW, Johnson JA, \& Emborg ME (2011) The PPAR- $\gamma$ agonist pioglitazone modulates inflammation and induces neuroprotection in parkinsonian monkeys. J Neuroinflammation, $\mathbf{8}, 91$

[125] Kim W, \& Egan JM (2008) The role of incretins in glucose homeostasis and diabetes treatment. Pharmacol Rev, 60, $470-512$.

[126] Meier JJ (2012) GLP-1 receptor agonists for individualized treatment of type 2 diabetes mellitus. Nat Rev Endocrinol, 8, 728-742.
[127] Perry T, Haughey NJ, Mattson MP, Egan JM, \& Greig NH (2002) Protection and reversal of excitotoxic neuronal damage by glucagon-like peptide-1 and exendin-4. J Pharmacol Exp Ther, 302, 881-888.

[128] Perry T, Lahiri DK, Sambamurti K, Chen D, Mattson MP, Egan JM, \& Greig NH (2003) Glucagon-like peptide-1 decreases endogenous amyloid-beta peptide (Abeta) levels and protects hippocampal neurons from death induced by Abeta and iron. J Neurosci Res, 72, 603-612.

[129] Li Y, Duffy KB, Ottinger MA, Ray B, Bailey JA, Holloway HW, Tweedie D, Perry T, Mattson MP, Kapogiannis D, Sambamurti K, Lahiri DK, \& Greig NH (2010) GLP-1 receptor stimulation reduces amyloid-beta peptide accumulation and cytotoxicity in cellular and animal models of Alzheimer's disease. J Alzheimers Dis, 19, 1205-1219.

[130] McClean PL, Parthsarathy V, Faivre E, \& Hölscher C (2011): The diabetes drug Liraglutide prevents degenerative processes in a mouse model of Alzheimer's disease. J Neurosci, 31, 6587-6594.

[131] Long-Smith CM, Manning S, McClean PL, Coakley MF, O'Halloran DJ, Holscher C, \& O'Neill C (2013) The diabetes drug liraglutide ameliorates aberrant insulin receptor localisation and signalling in parallel with decreasing both amyloid- $\beta$ plaque and glial pathology in a mouse model of Alzheimer's disease. Neuromolecular Med, 15, 102-114.

[132] Martin B, Golden E, Carlson OD, Pistell P, Zhou J, Kim W, Frank BP, Thomas S, Chadwick WA, Greig NH, Bates GP, Sathasivam K, Bernier M, Maudsley S, Mattson MP, \& Egan JM (2009) Exendin-4 improves glycemic control, ameliorates brain and pancreatic pathologies, and extends survival in a mouse model of Huntington's disease. Diabetes, $\mathbf{5 8}$, 318-328.

[133] Velmurugan K, Bouchard R, Mahaffey G, \& Pugazhenthi S (2012) Neuroprotective actions of glucagon-like peptide-1 in differentiated human neuroprogenitor cells. J Neurochem, 123, 919-391.

[134] Sakamoto K, Karelina K, \& Obrietan K (2011) CREB: A multifaceted regulator of neuronal plasticity and protection. J Neurochem, 116, 1-9.

[135] Mattson MP, Perry T, \& Greig NH (2003) Learning from the gut. Nat Med, 9, 1113-1115.

[136] Cheng B, \& Mattson MP (1994) NT-3 and BDNF protect CNS neurons against metabolic/excitotoxic insults. Brain Res, 640, 56-67.

[137] Levivier M, Przedborski S, Bencsics C, \& Kang UJ (1995) Intrastriatal implantation of fibroblasts genetically engineered to produce brain-derived neurotrophic factor prevents degeneration of dopaminergic neurons in a rat model of Parkinson's disease. J Neurosci, 15, 7810-7820.

[138] Li Y, Perry T, Kindy MS, Harvey BK, Tweedie D, Holloway HW, Powers K, Shen H, Egan JM, Sambamurti K, Brossi A, Lahiri DK, Mattson MP, Hoffer BJ, Wang Y, \& Greig NH (2009) GLP-1 receptor stimulation preserves primary cortical and dopaminergic neurons in cellular and rodent models of stroke and Parkinsonism. Proc Natl Acad Sci U S A, 106, 1285-1290.

[139] Radák Z, Naito H, Kaneko T, Tahara S, Nakamoto H, Takahashi R, Cardozo-Pelaez F, \& Goto S (2002) Exercise training decreases DNA damage and increases DNA repair and resistance against oxidative stress of proteins in aged rat skeletal muscle. Pflugers Arch, 445, 273-278.

[140] Jensen L, Schjerling P, \& Hellsten Y (2004) Regulation of VEGF and bFGF mRNA expression and other proliferative compounds in skeletal muscle cells. Angiogenesis, 7, 255267. 
[141] Morton JP, Kayani AC, McArdle A, \& Drust B (2009) The exercise-induced stress response of skeletal muscle, with specific emphasis on humans. Sports Med, 39, 643-662.

[142] Wohlgemuth SE, Seo AY, Marzetti E, Lees HA, \& Leeuwenburgh C (2010) Skeletal muscle autophagy and apoptosis during aging: Effects of calorie restriction and life-long exercise. Exp Gerontol, 45, 138-148.

[143] He C, Bassik MC, Moresi V, Sun K, Wei Y, Zou Z, An Z, Loh J, Fisher J, Sun Q, Korsmeyer S, Packer M, May HI, Hil JA, Virgin HW, Gilpin C, Xiao G, Bassel-Duby R, Scherer
PE, \& Levine B (2012) Exercise-induced BCL2-regulated autophagy is required for muscle glucose homeostasis. Nature, 481, 511-515.

[144] Lee S, \& Notterpek L (2013) Dietary restriction supports peripheral nerve health by enhancing endogenous protein quality control mechanisms. Exp Gerontol, 48, 10851090.

[145] Longo VD \& Mattson MP (2014) Fasting: molecular mechanisms and clinical applications. Cell Metab. doi: 10.1016/j.cmet.2013.12.008 [Epub ahead of print]. 